
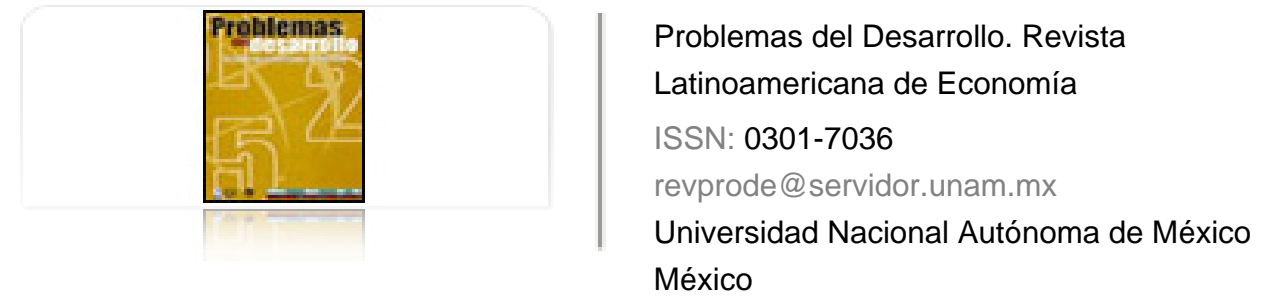

Reyes Guzmán, Gerardo; Muñoz Santiago, Bertha; Moslares García, Carlos

El tipo de cambio flexible y la política monetaria en México: 1995-2003

Problemas del Desarrollo. Revista Latinoamericana de Economía, vol. 35, núm. 136, 2004, pp. 49-63

Universidad Nacional Autónoma de México

Distrito Federal, México

Disponible en: http://www.redalyc.org/articulo.oa?id=11825946004

- Cómo citar el artículo

- Número completo

- Más información del artículo

Página de la revista en redalyc.org

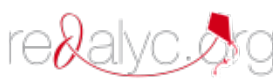

Sistema de Información Científica

Red de Revistas Científicas de América Latina, el Caribe, España y Portugal Proyecto académico sin fines de lucro, desarrollado bajo la iniciativa de acceso abierto 


\title{
EL TIPO DE CAMBIO FLEXIBLE Y LA POLÍTICA MONETARIA EN MÉxICO: 1995-2003
}

\author{
Gerardo Reyes Guzmán* \\ Bertha Muñoz Santiago** \\ y Carlos Moslares García ${ }^{* * *}$
}

Fecha de recepción: 20 de agosto de 2003. Fecha de aprobación: 14 de mayo de 2004.

\begin{abstract}
Resumen
El presente ensayo se ocupa de pormenorizar las características de la política monetaria y cambiaria a partir de 1995, contrastándolas con el régimen de tipo de cambio fijo, vigente antes de la crisis de 1994. El propósito es mostrar, por un lado, cómo los factores externos determinan con una intensidad creciente la paridad cambiaria en México, al tiempo que alimentan la volatilidad en los mercados financieros; y por el otro, resaltar la posibilidad de que el corto, como instrumento de política monetaria, esté perdiendo efectividad.

Palabras clave: tipos de cambios, libre flotación, política monetaria, mercados financieros, política cambiaria.

Abstract

This paper is concerned with detailing the characteristics of monetary and foreign exchange policy since 1995, contrasting them with the fixed exchange rate system which operated before the 1994 crisis. The proposal is, on the one hand, to show how external factors increasingly determine Mexico's exchange rate, while feeding volatility in the financial markets; and, on the other hand, to emphasize the possibility that the short, as an instrument of monetary policy, is losing its effectiveness.
\end{abstract}

Key terms: exchange rates, free float, monetary policy, financial markets, exchange rate policy.

* Profesor investigador de tiempo completo en la Universidad Iberoamericana $\sim$ Puebla, correo electrónico: gerardo.reyes@iberopuebla.net

* Profesora de tiempo parcial en la Universidad Iberoamericana Puebla, correo electrónico: bertha_santiago@yahoo.com

*** Profesor investigador de tiempo completo en el Instituto de Química de Sarría en Barcelona, España, correo electrónico: moslares@iqs.url.es 


\section{Résumé}

Le présent essai a pour but de comprendre les tenants et les aboutissants des caractéristiques de la politique monétaire et des changes à partir de 1995, en soulignant les contrastes entre celleci et le régime du taux de change fixe en vigueur avant la crise de 1994. L'objectif est de démontrer, d'une part, comment les facteurs externes déterminent avec une intensité croissante la parité des changes au Mexique tout en entretenant la volatilité des marchés financiers et, d'autre part, de mettre en évidence que le court terme, comme un instrument de politique monétaire, peut perdre peu à peu son caractère effectif.

Mots-clés: taux de change, flottement des monnaies, politique monétaire, marchés financiers, politique des changes.

\section{Resumo}

O presente ensaio mostra uma descrição pormenorizada das características da política monetária e cambial do México, a partir de 1995, contrastando-as com o regime de tipo de câmbio fixo, vigente antes da crise de 1994. O propósito é mostrar, por um lado, como os fatores externos determinam com intensidade crescente a paridade cambiária no México, alimentando a volatilidade nos mercados financeiros; e por outro lado, ressaltar a possibilidade de que o corto esteja perdendo efetividade, como instrumento de política monetária.

Palavras-chave: tipos de câmbios, livre flutuação, política monetária, mercados financeiros, política cambiária. 


\section{Introducción}

$\mathrm{D}$ urante la década de los noventa se desató una serie de crisis financieras, producto de la facilidad de movimiento de capitales que posibilitó la liberalización financiera en diversas economías emergentes. En virtud de la dimensión del daño económico y social emanado de dichas crisis, se pensó en un modelo cambiario que pudiera amortiguar los efectos negativos causados por la volatilidad del flujo de capitales, eligiéndose el tipo de cambio flexible (Caramazza, 1998). En plena etapa de superación del llamado error de diciembre, el gobierno mexicano optó por este modelo. Debido a las intervenciones que ha tenido el Banco de México (Banxico) en el mercado cambiario desde 1995 a la fecha, el modelo se conoce como flotación sucia o tipo de cambio flexible monitoreado. Esta modalidad encuentra su explicación en el papel que desempeña el Banco de México a partir de la obtención de su autonomía en 1993. De ahí destacan tres características: su independencia para determinar el volumen del crédito primario que pueda ser concedido, la independencia que se le ha otorgado a las personas que integran su Junta de Gobierno y la independencia administrativa de la institución. Según el artículo 28 constitucional, "ninguna autoridad podrá ordenar al Banco conceder financiamiento". En este mismo tenor, la Ley del Banco de México señala que Banxico debe, entre sus funciones, constituir y manejar las reservas que requiera el planteamiento de sus metas. Así el manejo de las reservas internacionales le permite al Banco de México garantizar la estabilidad del poder adquisitivo de la moneda nacional mediante la compensación de desequilibrios entre los ingresos y egresos de divisas del país (Cabello, 1999:175). El monto de las reservas y la política monetaria a través del llamado corto, son instrumentos que utiliza Banxico para incidir sobre la paridad peso-dólar, pues es la Secretaría de Hacienda la responsable directa de la política cambiaria. En este contexto, el tipo de cambio ha afectado directamente otras variables macroeconómicas como el sector externo, el mercado de capitales, el crecimiento económico, el salario real y el empleo. Del seguimiento e interpretación del mercado cambiario se desprende una serie de preguntas que invitan al debate y ameritan estudiarse con detenimiento.

Este trabajo tiene como propósito principal destacar comportamientos en el tipo de cambio que difícilmente pueden ser explicados con los modelos clásicos y, por otro lado, mostrar la posibilidad de que Banxico esté perdiendo su capacidad para incidir en la tasa de interés y el tipo de cambio, por medio del corto. Si este fuera el caso, la política monetaria debería ser repensada en virtud de que ha sido a menudo utilizada como muestra de soberanía nacional. La presente estabilidad macroeconómica descansa tanto en la política 
inflacionaria como en la cambiaria; sin embargo, el creciente desempleo, el déficit público y el aletargamiento de la economía se asoman como serias amenazas y hacen del equilibrio macroeconómico un elemento cada vez más superficial.

En la primera parte se revisan algunos postulados teóricos que nos permiten explicar el funcionamiento del tipo de cambio. Se comentan las características de la llamada paridad de poder adquisitivo, el enfoque monetario y el modelo de Dornbusch. La segunda sección resalta las experiencias más importantes en relación con la nueva política cambiaria de 1995 a 1999 en México, y analiza el mercado cambiario de 1999 a 2003 buscando un vínculo con el mercado de capitales, los precios del petróleo y la recesión de la economía norteamericana. Finalmente se concluye resaltando algunas ideas que podrían orientar análisis más profundos con respecto a la política cambiaria vigente en México a partir de 1995.

\section{El tipo de cambio}

Existe una vasta literatura con relación a modelos para estimar el tipo de cambio. Uno de los clásicos es el denominado paridad de poder de adquisitivo (PPA), que parte de la ley de un solo precio y explica la importancia del tipo de cambio real (TCR). Para estimar el valor real de una moneda se toma cuenta el índice de precios en el país socio en relación con el país base multiplicado por el tipo de cambio nominal. Una vez elegido el intervalo se puede calcular si una moneda está o no sobrevaluada, estableciéndose así un vínculo directo con el saldo de la balanza comercial. Un tipo de cambio sobrevaluado hará las exportaciones menos competitivas y abaratará las importaciones, lo que repercute ceteris paribus en un déficit en el comercio de mercancías y servicios con el exterior.

Se argumenta que la política cambiaria en México se ha utilizado como ancla inflacionaria, puesto que la sobrevaluación del peso ejerce directamente una presión en los precios a la baja. La Gráfica 1 muestra una estrecha correlación entre el tipo de cambio real y el comportamiento de los precios de 1990 a 2002.

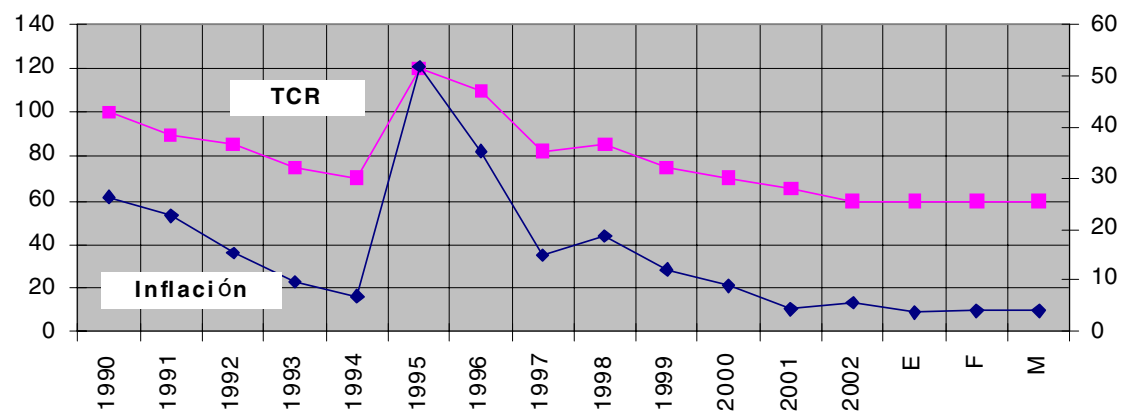

Gráfica 1. Tipo de cambio real e inflación en México.

Fuente: Enrique Dussel, citado por Felipe Garzón, 17 de junio de 2002; INEGI (2003), Información Estadística. http://www.inegi.gob.mx/difusion/espanol/fietab.html 
De 1990 a 1994 el tipo de cambio real tiende a sobrevaluarse, pues se aleja de $100 \%$ que simboliza el equilibrio. Paralelamente, el índice de precios presenta una relación muy estrecha, cristalizándose la tesis de que el tipo de cambio es usado como ancla para controlar la inflación. Nótese que el aumento de la sobrevaluación del peso coincide con un déficit agudo en la cuenta corriente, elemento que detonó la crisis financiera de diciembre de 1994 al tener lugar la macrodevaluación.

El ajuste cambiario se manifestó en un repunte inflacionario y en una ligera subvaluación del peso. A partir de 1996, la historia se repitió. El peso mexicano se sobrevalúa y la inflación tiende a la baja. ${ }^{1}$

Otro modelo que nos permite entender el comportamiento del tipo de cambio es el enfoque monetario. Análogamente, parte de la PPA en el cual la relación del nivel de precios entre el país socio y el país base determina el tipo de cambio. A su vez, el nivel de precios en ambos países se puede ver afectado por sus respectivos movimientos en la tasa de interés o el nivel de ingreso, lo que repercute en una apreciación o una depreciación de sus monedas. Se entiende entonces que, por ejemplo, un aumento de la tasa de interés reduce la oferta monetaria ceteris paribus y ejerce presión sobre los precios a la baja; esto hace que la moneda se aprecie. Así, la política monetaria tiene una influencia directa en el tipo de cambio. Una variación en el nivel de ingreso tendrá también efectos equivalentes. Bajo un régimen de tipo de cambio flexible, el equilibrio externo se garantiza mediante el funcionamiento del clásico postulado de David Hume conocido como la ley de autoregulación de los precios. El Banco Central puede neutralizar los ajustes que esta ley trae consigo a través de la política de esterilización. La capacidad explicativa de estos modelos encuentra sus límites al suponer la existencia de condiciones de competencia perfecta y de libre comercio.

Más recientemente, Rudiger Dornbusch (2000), desarrolló un modelo que explica el papel que juega el tipo de cambio en las economías latinoamericanas. El connotado economista distingue tres fases de estabilización del tipo de cambio:

a) La primera se presenta como una herramienta de gran utilidad y se deriva de las ventajas que emanan de una macrodevaluación, es decir, una etapa de subvaluación de la moneda. No es permanente, puesto que sólo es efímera y entre más se abuse de ella menor será su eficacia.

1 Las variaciones en la tasa de interés nominal afectan al tipo de cambio y éste a los precios. En una economía abierta cuyo volumen de comercio con el exterior asciende a más de $60 \%$ del PIB, la sobrevaluación de la moneda abarata las importaciones, incidiendo en presiones al déficit externo. Los precios internos tienden a bajar ante la mayor competitividad de productos importados (para profundizar en el papel que juegan las reservas en el Banco Central, véase el artículo de Guadalupe Mántey de Anguiano "Desaceleración Financiera y Protección Fiscal al Banco Central", Economía Informa, núm. 265, marzo 1998, pp. 15 20). 
b) En la segunda, la etapa de sobrevaluación se hace evidente. Sin embargo, un ajuste cambiario es, desde el punto de vista político, inadecuado. Por lo regular esta etapa va acompañada de crecimiento económico, aumento del salario real, afluencia de capital extranjero y confianza en el clima de negocios.

c) En la tercera, el nivel de sobrevaluación alcanza un nivel tan alto que el ajuste cambiario se vuelve cada vez más necesario. Se trata, por todos los medios, de evitar lo que tarde o temprano tendrá que llegar: una crisis devaluatoria.

Dornbusch establece una relación entre el tipo de cambio, el salario real y el equilibrio externo, cuya dinámica denomina triángulo latinoamericano. El salario real determina el nivel de bienestar y se mide en términos de dólares americanos. Así, una moneda sobrevaluada confiere bienestar social vía mayor poder adquisitivo en las importaciones.

En la Figura 1, $w$ representa un nivel de salario real que de no alcanzarse, provocaría protestas, huelgas o levantamientos sociales. $Y$ refleja el equilibrio económico con pleno empleo. Cualquier punto inferior significa desempleo, lo que a su vez estimula marginalidad y pobreza. $F F$ señala diferentes saldos del sector externo; en todos los puntos localizados arriba de esta línea se incurre en un déficit comercial, que coincide con salarios reales altos y pleno empleo. Por otro lado, aquellos por debajo de la misma acusan un superávit, pero asociado con desempleo y salarios bajos. Las letras $A B C$ forman el triángulo latinoamericano, que demuestra la imposibilidad de equilibrio externo, pleno empleo y salarios reales altos.

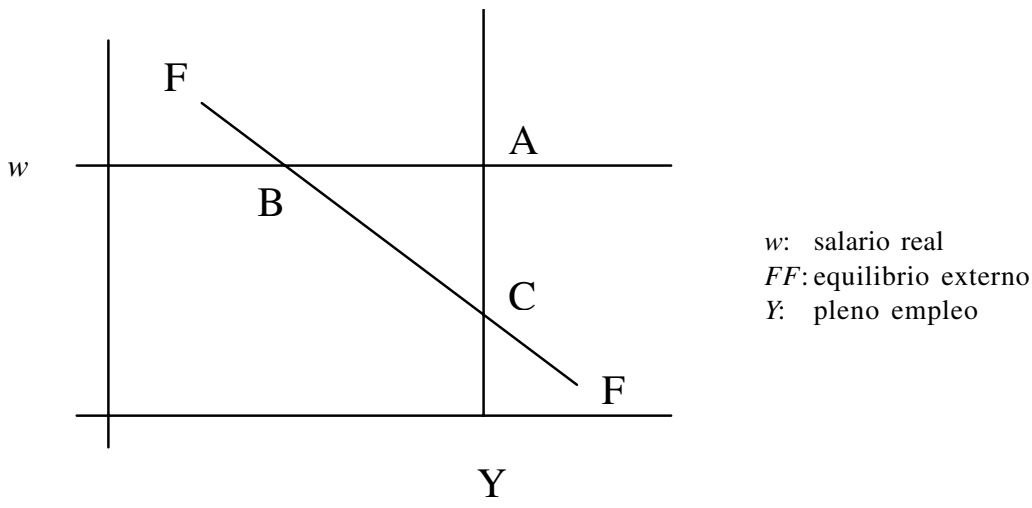

Figura 1.

El punto $A$ garantiza salarios altos y paz social (pleno empleo), pero a expensas de un agudo déficit externo. En el punto $B$ convergen tanto el equilibrio externo como salarios reales altos, pero con un desempleo que genera pobreza. En el punto $C$, se tiene pleno empleo y equilibrio externo, pero con salarios reales muy bajos, lo que alimenta protestas 
sociales. El punto que garantiza prosperidad en las economías latinoamericanas es el $A$, que representa al mismo tiempo un alto nivel de sobrevaluación de la moneda local. Éste se puede sostener a través de la afluencia de ahorro externo, es decir, endeudamiento. El problema se presenta cuando los flujos de capital se revierten o cuando el nivel de reservas de la Banca Central desciende a montos insuficientes para sostener el tipo de cambio. En tal caso, el ajuste cambiario se torna inevitable. La dimensión de la devaluación para corregir el desequilibrio externo dependerá de la elasticidad de las importaciones y exportaciones, tal y como lo prevé la condición Marshall-Lerner. Ante un ambiente de desconcierto, los mercados financieros pueden dejarse llevar por el pánico y generar una espiral inflación-devaluación que a su vez repercute en una recesión económica. Entre más tiempo permanezca la economía en el punto $A$, mayor será la necesidad de financiamiento externo (deuda), y más severa la magnitud del ajuste. La devaluación acompañada de políticas contractivas corrige el desequilibrio externo, pero genera recesión y desempleo. La inflación se convierte en el problema número uno a combatir y la política cambiaria aparece como la solución más viable. De inmediato comienza el proceso de apreciación que suprime el aumento de los precios y alivia el deterioro salarial. Para Dornbusch se trata del comienzo de una nueva crisis que tarde o temprano tendrá lugar.

La estrategia económica para combatir la inflación antes de la crisis de 1994-1995 se basó en el modelo de Dornbusch. El gobierno federal impulsó un proceso de sobrevaluación del peso mediante la instauración de un régimen cambiario semifijo con ligeros deslizamientos diarios al margen del diferencial inflacionario entre México y Estados Unidos. Ello propició la continua sobrevaluación de la moneda y el crecimiento del déficit comercial. Se suponía que el aumento de la productividad revertiría el desequilibrio externo al hacer las exportaciones más competitivas. Sin embargo, eso no sucedió. La amplia literatura acerca de las causas de la crisis económica de 1994-1995 en México coincide con el modelo de Dornbusch (Loria, 1997; Huerta 1995, Villareal, 2000). El punto A se caracterizó por un déficit en cuenta corriente del orden de 7\% del PIB; el peso acusaba niveles de sobrevaluación de más de $30 \%$ como lo señala la Gráfica 1 . La política cambiaria antiinflacionaria se basaba en la entrada de capitales vía privatizaciones, auge en el mercado bursátil, altas tasas de interés, endeudamiento público y privado y una apertura comercial desordenada (Huerta, 1995). Los ajustes cambiarios a través del deslizamiento del peso frente al dólar no pretendían corregir el desequilibrio externo, pues ello hubiera propiciado la reversión del flujo de capitales a raíz de la desvalorización de activos que trae consigo una devaluación. Sostener el nivel de sobrevaluación se tornaba cada vez más difícil en la medida que implicaba mayor endeudamiento interno, disminución de las reservas internacionales y una mayor exigencia de los inversionistas por obtener protección de sus activos de una devaluación vía adquisición de papel gubernamental indizado a dólares. Funcionarios del Banco Central asocian la caída de las reservas internacionales a factores políticos y sociales. 
Según ellos, los magnicidios propiciaron un descenso de las reservas del banco central desde 30 mil millones de dólares — antes del asesinato del candidato presidencial, Donaldo Colosio Murrieta - hasta 5 mil millones de dólares previo al abandono de la paridad cambiaria a las fuerzas del mercado. Arturo Huerta rechaza esta explicación, argumentando que "las reservas disminuyeron como resultado de la menor entrada de capitales, frente al creciente déficit externo, debido al riesgo cambiario que ello configuraba y por la incapacidad de pago de la economía mexicana frente a sus obligaciones" (Huerta, 1995:83). Tal y como lo señala Dornbusch, las autoridades hicieron lo posible por evitar el ajuste cambiario, inclusive contrayendo deuda de corto plazo mediante la oferta papel indizado a dólares conocido como tesobonos. Éstos proveyeron fondos adicionales a corto plazo del orden de 23 mil millones de dólares. A pesar del esfuerzo, no se logró contrarrestar el pánico que secuestró a los mercados financieros y sí se suscitó el efecto contrario. La crisis denominada efecto tequila se extendió a lo largo del continente afectando a Brasil y Argentina.

\section{Experiencias con el tipo de cambio flexible}

\section{7-1999}

Si bien el periodo anterior a la crisis de 1994 se explica sin dificultad con el modelo de Dornbusch, a partir de 1995, y una vez alcanzada la estabilización, la nueva política cambiaria presenta características contrastantes con el régimen anterior.

De 1997 a 1999 tuvo lugar una serie de acontecimientos internacionales que afectaron el desempeño de la economía nacional: la crisis asiática, la baja en los precios internacionales del petróleo, la crisis rusa y la crisis brasileña. Todos ellos se manifestaron en un ajuste cambiario, un deterioro en el clima de negocios reflejado en caídas abruptas de la Bolsa de Valores y un aumento de las tasas de interés. Al parecer, el tipo de cambio flexible logró sortear favorablemente las vicisitudes derivadas de estos choques externos. Banxico y la Secretaría de Hacienda pusieron en marcha políticas restrictivas que asfixiaron presiones inflacionarias restaurando la confianza en el clima de negocios. Se introdujo el corto que consiste en un monto que se coloca en la banca comercial al doble de la tasa de mercado dentro de la cantidad total que diariamente se solicita al Banco de México. ${ }^{2}$ La Secretaría de Hacienda ajustó el tipo de cambio como respuesta a la crisis asiática para restablecer la competitividad de las exportaciones. Si bien la meta inflacionaria no fue alcanzada

2 A diferencia de otros bancos centrales como los de Chile, Israel o Polonia, Banxico no ha utilizado un mecanismo de señalización de la intención monetaria como la tasa de referencia. México es el único de los países de la OCDE que no lo hace. En su lugar diseñó un mecanismo llamado corto que permite un ajuste en la tasa de interés de acuerdo con las metas de política monetaria. Durante la segunda mitad de la década de los noventa, cuando la inflación marcaba niveles de $25 \%$ anual, la aplicación del corto resulto sumamente favorable. Una vez que la inflación descendió a un dígito, el fMI ha recomendado a México el uso de la tasa de referencia a corto plazo. 
exitosamente por dichas políticas, la demanda sí sufrió un efecto contractivo incidiendo en un freno al crecimiento económico. La caída de los precios internacionales de petróleo en 1998 se tradujo en severos recortes al gasto público que a su vez se hicieron presentes en un deterioro social. Ante la incertidumbre financiera que provocaron dichos eventos, el gobierno federal diseñó el llamado blindaje financiero, que consistió en contratar una línea de crédito con el Fondo Monetario Internacional y otras instituciones financieras. De 1999 a 2001 se extendieron líneas de crédito por los siguientes montos: 19992000, 23 mil millones de dólares; 2000-2001, 26 mil 400 millones de dólares; y en 2001, 15 mil millones de dólares. El endeudamiento externo no aumentó, puesto que no se hizo uso del crédito y sólo sirvió para estabilizar el clima de negocios, así como para desalentar la especulación en contra del peso. Durante este periodo se generó una continua sobrevaluación de la moneda nacional que no se corrigió con los ajustes al tipo de cambio durante las crisis. No obstante, las políticas cambiaria, monetaria y fiscal parecieron sortear exitosamente los choques externos.

\section{0-2003}

Durante 2001 la entrada de capital extranjero en México fue inusitada. La fusiones de los bancos mexicanos más grandes con bancos internacionales constituyeron el concepto más importante de inversión extranjera en el periodo: Banamex-Citigroup, Bancomer-BBv y Serfin-Santander. En el resumen de la balanza de pagos de la Tabla 1 se observa en el renglón de inversión extranjera directa repuntes importantes entre 2000 y 2002. De los 26 mil 569 millones de dólares captados en 2001, 46\% es atribuible a la fusión Banamex Citigroup. Para 2003, ésta cerró en 10 mil 731 millones de dólares, cifra inferior a las remesas (13 mil 266 millones de dólares) y a las exportaciones de crudo (16 mil 835 millones de dólares) para ese año. Si omitimos las operaciones anteriores, el comportamiento comienza a despertar sospechas de una pérdida paulatina de la capacidad de México para atraer IED. Por ejemplo, la participación de ésta en un PIB aproximado de 442 mil millones de dólares para 1998, fue de $2.75 \%$. El PIB para 2003 se ubicó alrededor de 635 mil millones de dólares, mientras que la IED sólo representó $1.68 \% .^{3}$

Por otro lado, la política monetaria contractiva mantuvo tasas de interés muy altas en comparación con los niveles internacionales del momento, lo que a su vez incentivó una entrada aún mayor de capital extranjero. Ello obligó al Banco Central a esterilizar esta afluencia de divisas para evitar un crecimiento discrecional de la base monetaria y su repercusión en el nivel de precios. La política de esterilización resultó costosa porque

3 Una característica de la estructura actual de la IED consiste en que antes de la crisis de 1994 ésta se concentraba en el terreno especulativo y ahora lo hace en el productivo, lo que incide en un menor nivel de volatilidad (véase la Tabla1). 
Tabla 1

Resumen de la balanza de pagos (miles de millones de dólares)

\begin{tabular}{|c|c|c|c|c|c|c|}
\hline Concepto & 1998 & 1999 & 2000 & 2001 & 2002 & 2003 \\
\hline Saldo de la cuenta corriente & -16072.4 & -14000.6 & -18167.0 & -18157.9 & -14053.3 & -9237.6 \\
\hline Ingresos & 140068.8 & 158939.9 & 193280.9 & 185601.7 & 187856.5 & 195009.0 \\
\hline Exportación de mercancías & 117459.6 & 136391.1 & 166454.8 & 158442.9 & 160762.7 & 164860.2 \\
\hline Servicios no factoriales & 11522.6 & 11692.0 & 13712.3 & 12660.3 & 12691.6 & 12658.3 \\
\hline Servicios factoriales & 5047.1 & 4516.8 & 6090.7 & 5138.6 & 4098.5 & 3725.8 \\
\hline Transferencias & 6039.5 & 6340.0 & 7023.1 & 9360.0 & 10303.7 & 13764.6 \\
\hline Egresos & 156141.1 & 172940.5 & 211447.9 & 203759.6 & 201909.8 & 204246.6 \\
\hline Importación de mercancías & 125373.1 & 141974.8 & 174457.8 & 168396.5 & 168678.9 & 170550.6 \\
\hline Servicios no factoriales & 12427.5 & 13490.6 & 16035.7 & 16217.9 & 16739.7 & 17125.3 \\
\hline Servicios factoriales & 18313.4 & 17448.2 & 20925.0 & 19123.4 & 16456.0 & 16533.6 \\
\hline Transferencias & 27.1 & 26.9 & 29.4 & 21.9 & 35.2 & 37.1 \\
\hline Saldo de la cuenta de capital & 18560.4 & 13878.7 & 18325.5 & 25402.3 & 22230.8 & 17528.4 \\
\hline Pasivos & 18128.9 & 17883.4 & 11226.4 & 29236.9 & 10426.1 & 10561.8 \\
\hline Por préstamos y depósitos & 4932.4 & -7287.2 & -4088.0 & -1214.4 & -3377.3 & -4033.5 \\
\hline Inversión extranjera & 13196.5 & 25170.6 & 15314.4 & 30451.3 & 13803.4 & 14595.3 \\
\hline Directa & 12169.5 & 13165.7 & 16448.7 & 26569.3 & 14435.3 & 10731.4 \\
\hline De cartera & 1027.0 & 12004.9 & -1134.3 & 3882.1 & -632.0 & 3863.9 \\
\hline Activos & 431.5 & -4004.7 & 7099.0 & -3834.6 & 11804.7 & 6966.6 \\
\hline Errores y omisiones & -349.6 & 714.1 & 2665.7 & 80.7 & -1087.8 & 1146.9 \\
\hline Variación de la reserva neta & 2136.9 & 593.6 & 2821.5 & 7325.0 & 7104.1 & 9450.9 \\
\hline Ajustes por valoración & 1.5 & -1.4 & 2.7 & 0.0 & -14.4 & -13.2 \\
\hline
\end{tabular}

Fuente: INEGI, http://www.inegi.gob.mx/est/contenidos/espanol/tematicos/mediano/med.asp? $t=e$ ext $22 \& c=2547$

implicaba un crecimiento del endeudamiento interno por un lado, y del externo por el otro. Ante un aumento de las reservas internacionales, el Banco Central enfrentaba rendimientos inferiores por los dólares depositados en títulos del tesoro norteamericano, en comparación con la tasa de interés de sus obligaciones internas. La afluencia de capital se vio reforzada por un crecimiento extraordinario de las remesas o fondos transferidos por trabajadores mexicanos instalados en Estados Unidos.

De diciembre de 2000 a febrero de 2002, el tipo de cambio nominal se apreció en $5.2 \%$ al pasar de \$9.57 a \$9.07 por dólar. Este movimiento se asocia con la decisión de las agencias calificadoras Moody's, Standard \& Poors y Fitch de otorgar a México un grado de inversión BBB-. El índice de riesgo país, medido por la diferencia en puntos porcentuales entre bonos del tesoro y deuda gubernamental, bajó de 320 en enero a 230 en marzo, indicando una mejora sustancial de la confianza de los inversionistas en México. Con ello, la moneda mexicana alcanzó niveles de sobrevaluación tan agudos que los sectores manufacturero y maquilador solicitaron a Banxico una intervención en el mercado cambiario para disuadir el desequilibrio. Al mismo tiempo la crisis de Norteamérica hizo que la demanda de exportaciones disminuyera, hecho que se reflejó en una drástica contracción del comercio y déficit externos. El déficit comercial cayó de 2.8\% como porcentaje del PIB en 2001 
a $2.2 \%$ en 2002. El déficit de la cuenta corriente también disminuyó de 18 mil 167 millones de dólares en 2000 a 9 mil 237 millones en 2003. Esta caída se explica en parte por las remesas (registradas en el apartado de transferencias) y el aletargamiento del comercio exterior. En la balanza de pagos (Tabla 1) se percibe en el rubro de ingresos por concepto de transferencias un aumento en el mismo periodo de 7 mil 23 millones de dólares a 13 mil 764 millones de dólares. Las exportaciones se redujeron de 166 mil millones de dólares en 2000 a 160 mil millones de dólares en 2002; las importaciones lo hicieron de 174 mil millones de dólares a 168 mil millones de dólares en el mismo periodo.

En agosto de 2002, el triunfo político de Ignâcio Lula da Silva en Brasil y el clima bélico de Medio Oriente se reflejaron en una caída abrupta de la Bolsa Mexicana de Valores y un nuevo ajuste al tipo de cambio. Esta vez se rebasó la barrera psicológica de los $\$ 10.00$ por dólar, disminuyendo el porcentaje de apreciación de la moneda nacional. Todo ajuste ligado a una pérdida del valor de la moneda supone una presión a la alza en el nivel de precios. La Gráfica 2 muestra el aumento del corto de 300 millones a 400 millones en septiembre de 2002 y de 400 millones a 700 millones en el primer semestre de 2003. A pesar de todo la inflación cerró en $5.7 \%$ anual en 2002, nivel superior a la meta de $4.5 \%$; las autoridades explicaron que ésta no había sido alcanzada por el alza en los precios del gas y la electricidad. Paralelamente, la economía alcanzó un magro crecimiento de $0.9 \%$, y el déficit público cerró en $1.25 \%$ con respecto al PIB en lugar de $0.65 \%$ planeado. El gobierno atribuyó el desajuste fiscal a la quiebra de Banrural en ese mismo año.

Durante 2003 el peso comenzó a depreciarse con respecto al dólar. Esta tendencia coincide con los preparativos de la guerra en Irak, el debilitamiento del dólar con respecto al euro y el aumento de los precios del crudo. Paralelamente, las reservas de Banxico registraban una preocupante tendencia a la alza. En virtud de la volatilidad en el mercado cambiario, se decide aumentar el corto a 700 millones de pesos mensuales en aras de apuntalar la tasa de interés y estabilizar el tipo de cambio. Paralelamente, el Banco Central anuncia una intervención en el mercado cambiario por un monto de divisas proporcional

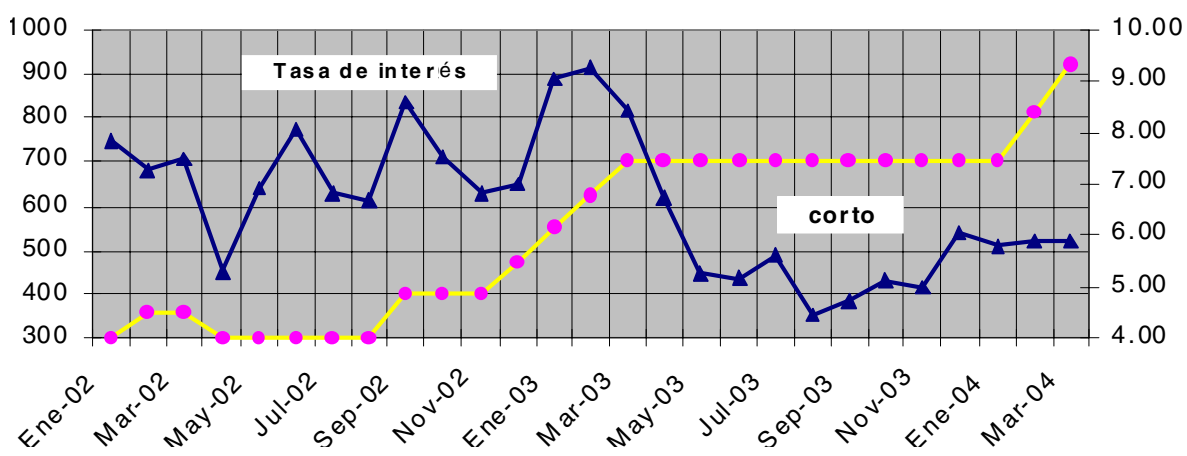

Gráfica 2. Política monetaria y tasa de interés (CETES).

Fuente: elaboración propia con datos del INEGI. 


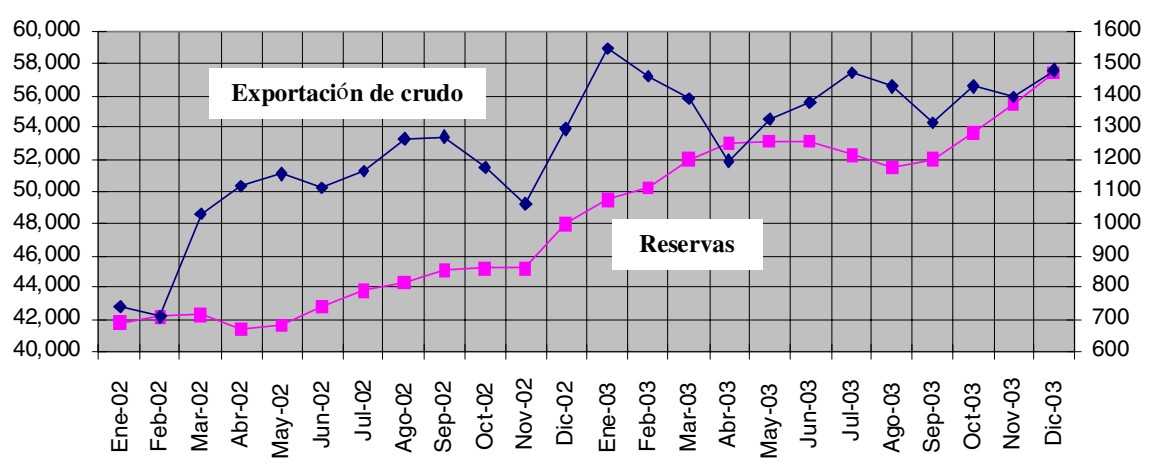

Gráfica 3. Exportaciones de petróleo (mdd) y nivel de reservas de divisas (mmd).

Fuente: elaboración propia con datos del INEGI.

al recibido por concepto de ingresos de exportación de crudo, reduciendo así la velocidad de acumulación de reservas. De mayo de 2003 a marzo de 2004, Banxico ha subastado 4 mil 661 millones de dólares en el mercado cambiario. Esta política ha tenido el efecto esperado sólo en el muy corto plazo, puesto que el tipo de cambio ha seguido perdiendo valor. Desde que comenzó la operación de subasta en mayo de 2003 a la fecha, la moneda ha pasado de \$10.50 a \$11.50 por dólar para el primer semestre de 2004 .

En la Gráfica 3 se aprecia la estrecha relación entre las exportaciones de crudo en millones de dólares (mmd) durante 2003 y el aumento de reservas del Banco Central. El precio promedio de la mezcla mexicana se mantuvo por arriba de los 25 dólares por barril, lo que significó una importante entrada de divisas al país. Otro aspecto relevante es el repunte acelerado en el IPC de la Bolsa Mexicana de Valores. De enero de 2003 a febrero de 2004 se elevó de 5600 puntos a 10 000, fenómeno que se explica por un comportamiento similar en el NASDAQ y el Dow Jones, índices que reflejan la recuperación económica de Estados Unidos. Esto podría estar incidiendo en el fortalecimiento del dólar. El incremento en el PIB de 2003 fue de $1.4 \%$, lo que señala una ligera recuperación en el crecimiento económico. Sin embargo, uno de los desequilibrios que más preocupan es el desempleo. Éste alcanzo niveles cercanos a 4\%, cifra inusitada en tiempos de estabilidad macroeconómica.

\section{Conclusiones}

Hemos dado lectura a tres modelos que explican el funcionamiento del tipo de cambio, encontrando una gran utilidad en el último, desarrollado por el connotado y fallecido economista Rudiger Dornbusch. Con ayuda del triángulo latinoamericano se entiende de manera sencilla el papel de la política cambiaria en la crisis mexicana de 1994-1995, pues se trataba de un tipo de cambio semifijo con una clara intervención del gobierno federal para determinarlo.

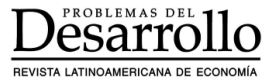


A partir de 1995, las experiencias con el tipo de cambio presentan características más complejas que dificultan comprender su funcionamiento. Con base en los modelos clásicos, se puede identificar un porcentaje de sobrevaluación del peso a partir de 1997. Si bien se puede afirmar que la política cambiaria se utiliza como instrumento antiiflacionario como en el pasado, los niveles de sobrevaluación no son constantes ni crecientes. Ahora existe un papel protagónico por parte del Banco de México en su manejo de la política monetaria desde 1998 a través del llamado corto. Éste persigue influir sobre la tasa de interés para reducir presiones inflacionarias. A su vez, los movimientos en el costo del dinero afectan la oferta monetaria e indirectamente el tipo de cambio. Los modelos clásicos nos explican que una política restrictiva aumenta la tasa de interés y aprecia el tipo de cambio en el corto plazo. Este mecanismo le confiere a Banxico la posibilidad de incidir sobre la paridad cambiaria bajo un régimen de tipo de cambio flexible. Las intervenciones directas en el mercado cambiario han sido discretas, en afán de respetar la nueva política cambiaria y no dar señales equivocadas al mercado. La eficacia del corto para finales de la década de los 90 es evidente, pero de 2000 a la fecha, la capacidad de influencia en las tasas de interés y la reducción en el nivel de precios muestra una pérdida de dinamismo. Aun cuando los niveles de inflación se mantengan bajos, no son los que se tienen programados, por lo que el Banco Central continúa priorizando la meta inflacionaria en relación con el crecimiento económico y el empleo. Por un lado, se observa con más frecuencia que el tipo de cambio obedece cada vez más a factores externos como el grado de inversión otorgado por las calificadoras a la deuda mexicana, el proceso de fusiones y adquisiciones en el sector bancario, las exportaciones de petróleo en relación con precios altos en el mercado internacional, inversión extranjera directa, las remesas, las tasas de interés de Estados Unidos. Por el otro, el corto como instrumento de política monetaria parece perder filo. Desde 2003, las tasas de interés tienden a la baja, mientras que el monto del corto es cada vez mayor, lo que se contrapone a un repunte esperado en el costo del dinero y una reducción de la oferta monetaria. A partir de 2004, el aumento ha sido extraordinario: en febrero pasó de 700 millones a 812 millones; en marzo, de 812 millones a 924 millones y el 27 de abril, de 812 millones a 1036 millones, es decir, un incremento de 50\% en tres meses. Sin embargo, la tasa de interés se movió sólo de $5.65 \%$ a $6.0 \%$ alcanzando un nivel máximo de $6.59 \%$ en marzo. La drástica medida obedece al alza de los precios a principios de 2004, que si bien se explica por factores externos como la prohibición de compra de carne proveniente de los Estados Unidos a raíz de la presencia del síndrome encefalopatía epongiforme bovina (ЕЕB) o mal de las vacas locas, la inflación ha comenzado ya a incidir sobre las revisiones salariales. No obstante, el tipo de cambio se ha mantenido por el rango de $\$ 11.10$ y $\$ 11.50$ pesos por dólar y la inflación se mantuvo arriba de $4.0 \%$. Ni la política de subasta de reservas ni el corto han incidido en una apreciación importante de la moneda, aunque quizás hayan contribuido a detener su tendencia depreciatoria. En 
contraste, en agosto-septiembre de 2002, el corto aumentó de 300 millones a 400 millones, la tasa de interés subió de $6.69 \%$ a $8.60 \%$ en el mismo periodo; el tipo de cambio se apreció de $\$ 10.22$ en septiembre a $\$ 10.15$ pesos por dólar en octubre y la inflación se redujo de $5.51 \%$ en julio a $4.94 \%$ en octubre en términos anuales. Finalmente se plantean algunas tesis que pueden ser objeto de análisis más rigurosos:

a) El modelo de Dornbusch explica la mecánica del tipo de cambio fijo bajo una estructura económica inserta en la realidad latinoamericana en donde la sobrevalaución es un instrumento antiinflacionario al tiempo que impulsa el crecimiento a expensas de un déficit externo. La sobrevaluación del tipo de cambio funge como factor de bienestar al aumentar el poder adquisitivo en términos de dólares americanos. En México, bajo un tipo de cambio de flotación sucia, la sobrevaluación continúa siendo un ancla inflacionaria, pero con menor intensidad. El desequilibrio externo es modesto, pero el crecimiento económico es débil y el desempleo agudo.

b) El tipo de cambio puede ser modificado a través de la política monetaria vía corto. El aumento de éste debería reducir la oferta monetaria, encarecer el costo del dinero y apreciar el tipo de cambio en el corto plazo. Los incrementos excesivos en el corto y su modesta influencia en la tasa de interés, los niveles inflacionarios y el tipo de cambio, hacen pensar que este instrumento se está agotando y que quizá sea tiempo de aplicar una tasa de referencia como en Estados Unidos.

c) El tipo de cambio se torna cada vez más volátil al ser determinado por factores externos y vulnera el desempeño económico, puesto que limita la planeación de los agentes económicos en el mediano plazo, dificulta el control de la inflación, debilita al sector externo y desincentiva la inversión extranjera. En este tenor, la revisión inminente de las tasas de interés en Estados Unidos al alza para 2004, seguramente provocará mayores presiones devaluatorias con un esperado aumento del corto en afán de lograr un repunte en las tasas de interés internas, y así, poder contrarrestar este choque externo. No debemos olvidar que durante 1993-1994, el alza de intereses en Estados Unidos también favoreció la salida de capital.

La liberalización financiera continúa causando estragos en las economías emergentes. El reciente fracaso del experimento argentino con la caja de conversión complica la elección de una política cambiaria adecuada para contrarrestar eficientemente los choques externos. Muchos países parecen optar por un tipo de cambio de flotación sucia, pero siguen dependiendo del capital extranjero para mantener su estabilidad macroeconómica. En este contexto, se sigue privilegiando el combate a la inflación sobre el crecimiento económico y el pleno empleo. Ante la falta de alternativas, los países participan en una lucha vehemente por atraer flujos de IED, aun cuando ello implique una paulatina pérdida de su soberanía. 


\section{Bibliografía}

Banco de México, Informe Anual 2002, abril, 2003. Bowers David, "Mayor debilidad del dólar", en El Financiero, 26 de julio, 2002, p. 8.

Cabello Alejandra, Globalización y liberalización financieras y la Bolsa Mexicana de Valores. Del auge a la crisis, México, Plaza y Valdés, 1999.

Caramazza, Francesco y Jahangir Aziz, Fixed or Flexible? Getting the Exchange Rate Right in the 1990's. International Monetary Fond, abril de 1998, http://Www.imf.org/external/pubs/ft/issues13/ index.htm

Dornbusch, Rudiger, Keys of prosperity, Free markets, Sound Money, and a bit of Luck, London, MIT, 2000.

Garzón, Felipe, “Apreciación del tipo de cambio de $40 \%$ desde 1990”, El Financiero, 17 de junio de 2002, p. 5 .

Hernández Morón, Leticia, “Ahonda su caída el peso; el dólar en 11.35", El Financiero, 5 de marzo de 2003, p. 5.

Huerta, Arturo, Causas y Remedios de la Crisis Económica de México, México, Diana, 1995.

$\longrightarrow$, Carteras vencidas, inestabilidad financiera. Propuestas de solución, México, Diana, 1997.

INEGI, Información Estadística, 2003, http://wWw. inegi.gob.mx/difusion/espanol/fietab.html

_ http://www.inegi.gob.mx/est/contenidos/espanol $/$ tematicos/mediano/med.asp?t $=$ eext $22 \& c=2547$

Loria, Eduardo, "El tipo de cambio: una revisión de la crisis y un pronóstico", Economía Informa, núm. 259, unAM, julio-agosto de 1997, pp. 33-40.

Mántey de Anguiano, Guadalupe, "Desregulación financiera y protección fiscal al banco central", Economía Informa, núm. 265, marzo de 1998, pp. 15-20.
Mayoral, Isabel y Felipe Gazcón, “Adoptará Banxico medidas para hacer más exacta la aplicación del corto", El Financiero, 25 de marzo de 2003, p.6. , "Otorga Standard and Poors grado de inversión a la deuda soberana de México", El Financiero, 8 de febrero de 2002, p. 4.

Mota Aragón, Beatriz y Guillermo Martínez Antillano, "Dinámica de la volatilidad del tipo de cambio", Comercio Exterior, vol., 049, núm.5, mayo de 1999, p. 455.

Sandoval, Antonio, "Registra el dólar la peor jornada del año en centros cambiarios mundiales; euro en 0.9669; máximo de 2 años", El Financiero, Mercados, 21 de junio de 2002, p. 3.

, "La sobrevaluación del peso en su nivel más bajo desde septiembre de 1998: 22.5\%", El Financiero, Análisis Económico, 5 de febrero de 2003, p. 3.

_, "Ignoran las reservas Internacionales la inestabilidad cambiaria", El Financiero, Mercados, 26 de febrero de 2003, p. 34.

Sandoval, Rafael, "Podría el ajuste cambiario contaminar los precios finales, obstaculizando la meta inflacionaria de $3.0 \%$ para este año", El Financiero, Análisis Económico, 4 de abril de 2003, p. 4.

Solís Mendoza, Benito, "La apreciación del tipo de cambio real", El Financiero, Opinión, 2 de abril de 2002 , p. 35

Stiglitz, Joseph, Globalization and its discontents, New York, Norton and Company, 2002.

Villareal, René, Industrialización, deuda y desequilibrio externo en México. Un enfoque macroindustrial y financiero (1924-2000), México, FCE, 2000. 